\title{
Phenol Biosorption from Polluted Aqueous Solutions by Ulva lactuca Alga Using Batch Mode Unit
}

\author{
Mohammed Nsaif Abbas ${ }^{1}$, Suadat Mustafa Mohammed Al-Hermizy², \\ Zaidun Naji Abudi ${ }^{*}$, Thekra Atta Ibrahim³ \\ 1 Environmental Engineering Department, College of Engineering, Mustansiriyah University, Iraq \\ 2 Department of Biology, College of Science, Tikrit University, Iraq \\ 3 Department of Biology, College of Education for Pure Science, Diyala University, Iraq \\ * Corresponding author's e-mail: Zaidun.naji77@uomustansiriyah.edu.iq
}

\begin{abstract}
This paper is related to study the using sea lettuce (Ulva lactuca) as a low-cost adsorbent for removing the phenol compounds from aqueous solutions by adsorption under different operating conditions in a batch unit. The SEM and FTIR tests were performed to determine the morphological characteristics and the functional groups existing on the adsorbent material, respectively, while the surface area was identified by means of two techniques which were blue color method and BET method. The results of the adsorption experiments showed that the efficiency of the removal process is inversely proportional with initial concentration of phenol, $\mathrm{pH}$ and temperature; while the efficiency was directly proportional to adsorbent amount, agitation speed and treatment time. The results showed that the percentage of removal of phenol from processed water solutions ranged from $25.446 \%$ to $90.125 \%$. The Langmuir and Freundlich isotherm models were chosen to estimate the amounts of phenol adsorption by the sea lettuce powder. The kinetic study shows that the adsorption was obeyed pseudo second order also the thermodynamic parameters were calculated.
\end{abstract}

Keywords: Sea lettuce (Ulva lactuca), adsorption, phenol, aqueous solutions, isotherm, thermodynamic

\section{INTRODUCTION}

Day by day, the need of water quality improvement and preservation is increasing, due to the unconditional importance to life. Numerous sources pollute our valuable water resources. Different events like increased industrialization, agricultural, global environmental changes, and several anthropogenic activities lead to major world pollution. The wastewater containing organic contaminants (such as phenolic compounds) causes serious problems, due to their high toxicity, poor biodegradability, and possible accumulation in the environment. Phenol is discharged into the environment from many industries such as plastic, rubber, leather, pharmaceuticals, paint, petrochemicals, and pesticides, among others (Banat et al., 2000; Lazo-Cannata et al., 2011; Lin \& Juang, 2009). Phenols and its derivative compounds are considered as priority pollutants since they are harmful to human life even at very low concentrations and many of them are classified as hazardous pollutants because of their potential harm to the human health. According to Environmental Protection Agency (EPA) and the World Health Organization (WHO), regulations demand lowering the phenol content in wastewater and water to less than $1 \mathrm{mg} / \mathrm{L}$ and $1 \mu \mathrm{g} / \mathrm{L}$, respectively (D'Alessandro et al., 2014). Some of phenol effects on human health, occurring when contaminated water is used, include degeneration of proteins, tissue erosion, kidney damage, and paralysis of central nervous system (Senturk et al., 2009).

In order to remove the phenol and its derivatives from aqueous solutions, different processes 
have been employed such as electrocoagulation (Olya \& Pirkarami, 2013), ozonation (Cheng et al., 2018), biological treatment (Nakhli et al., 2014), extraction (Yang et al., 2014), electrofenton process (Asgari et al., 2016), photocatalytic (Vaiano et al., 2018), and adsorption (Wang et al., 2019). Among all the removal processes mentioned above, the adsorption process is the most widely used because of it is an economical and eco-friendly technology, reversible, rapid, which can be used in many situations for to minimize the environmental pollution (Alalwan et al., 2018; D'Alessandro et al., 2014). Studies have been carried out in order to find effective and low-cost natural adsorbents (biomass), such as fungi, algae, bacteria, etc., for the treatment of phenolic waste. Among different biomass materials, the algae constitute an excellent biosorbent material because of high adsorption coefficients, the low-cost, low sensitivity to environmental and impurity factors, and its excellent retention capacity, comparable in some cased with those of synthetic resin (Chen et al., 2011; Gavrilescu, 2004; Lodeiro et al., 2006). Various red, green and brown seaweeds were investigated by many scientists, in recent years, for the biosorption of metals and other pollutants (Areco \& dos Santos Afonso, 2010; Areco et al., 2012; Basha et al., 2008; Davis et al., 2000; Park et al., 2007), but there is a lack of or no information regarding the capacity of this seaweed to be used for phenol adsorption.

The Ulva lactuca, as one of the biosorbent materials which used in this study to remove phenol, is a kind of marine green algae. It is available in large quantities, and can be considered a cheap sorbent biomass. In addition, this material is particularly useful in the biosorption process of heavy metals due to its high surface area, relatively simple structure, small and uniform distribution of binding sites (Sar1 \& Tuzen, 2008; Turner et al., 2007). In this work, the main objective of the present study was to use Ulva lactuca as biosorbent for the removal of phenol from simulated synthetic wastewater. Additionally, different environmental conditions, namely $\mathrm{pH}$, temperature, the amount of biomass and the contact time were studied. Two isotherm models (Langmuir and Freundlich) and two kinetic models (pseudo-first order and pseudo-second order) were used for the mathematical description of phenol biosorption by marine green algae.

\section{EXPERIMENTAL WORK}

\section{Preparation of the biosorbent sea lettuce}

The adsorbent algae - sea lettuce (Ulva lactu$c a$ ) - used in this study were collected from different sites at Fao city, Basrah governorate, in the southern of Iraq. The collected Ulva lactuca was, firstly, washed with deionized water and then dried in an electric oven at $40^{\circ} \mathrm{C}$ overnight. Then, it was ground in a home electrical grinder to pieces ranging from 0.5 to $1 \mathrm{~mm}$ length. Finally, the biosorbent was preserved at laboratory fridge until used.

\section{Preparation of stock solution of phenol}

The phenol used in this study was supplied by Sigma-Aldrich Co., Germany and it was used without any further purification. The preparation of $1 \mathrm{mg} / \mathrm{l}$ of stock solution included dissolving $1.0 \mathrm{~g}$ of phenol in one litre of double distilled water. The different concentrations of solutions used in laboratory experiments were synthesized by diluting the stock solution to desired concentration which ranged between $5-100 \mathrm{mg} / \mathrm{l}$ of phenol. The concentration of phenol can be measured using the UV/VIS spectrophotometer at $\lambda_{\max }=270 \mathrm{~nm}$ and the calibration curve prepared for this purpose is showing in Figure 1.

\section{Adsorption experiments}

This study checked several operating parameters to identify the best conditions for the process of phenol removal in the batch-type adsorption unit using sea lettuce (Ulva lactuca) algae as an adsorbent material. In the study, $100 \mathrm{ml}$ of phenol solution at the determined concentration and a particular $\mathrm{pH}$ value was placed with a selected amount of biosorbent in a $150 \mathrm{ml}$ conical flask. The adsorption experiments were performed in an orbital water bath electric shaker (Innova 4080, The New Brunswick Scientific Company) using uniform mixing speeds, specific contact times and at the certain temperature. The $\mathrm{pH}$ of the phenol solution was fixed using $0.1 \mathrm{~N}$ of $\mathrm{NaOH}$ and $0.1 \mathrm{~N}$ of $\mathrm{HCl}$. In order to determine the best operating conditions, the adsorption experiments were carried out at different initial concentrations of phenol, $\mathrm{pH}$, agitation speed, contact time, adsorbent amount and temperature. These parameters were changed at the ranges $(1-100 \mathrm{mg} / \mathrm{l}),(1-9)$, (100-500 rpm), (15-180 min.), (0.5-2.5 g) and 


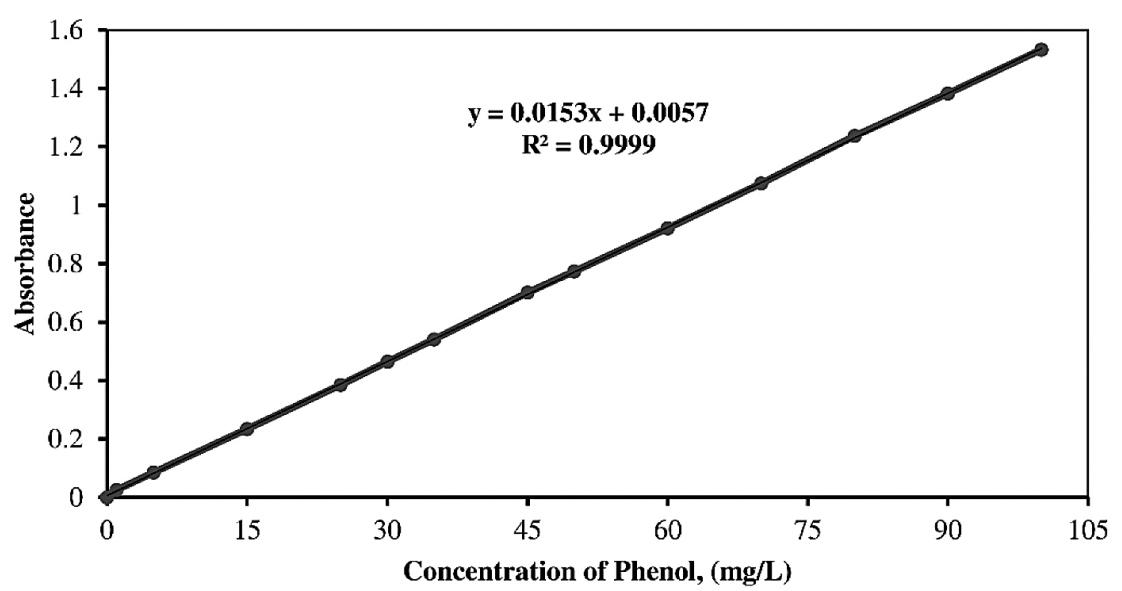

Figure 1. UV/VIS spectrophotometer calibration curve of phenol

$\left(20-50^{\circ} \mathrm{C}\right)$, respectively. After the experiment was completed, the sample was filtered with What$\operatorname{man}^{\circledR}$ qualitative filter paper, Grade 1 of $11 \mu \mathrm{m}$ and $87 \mathrm{~g} / \mathrm{m}^{2}$. The non-adsorbed concentration of phenol was detected using the UV/VIS spectrophotometer device. All experiments were executed triplicate for greater accuracy. The amounts of phenol adsorbed by biosorbent were determined by the following equation:

$$
q=\frac{V}{m}\left(C_{i}-C_{o}\right)(1)
$$

where: $q$ - adsorption capacity which is the amount of phenol adsorbed per unit of adsorbent (sea lettuce) $(\mathrm{mg} / \mathrm{g})$;

$V$-volume of solution used in the experiment (1);

$C_{i}$ and $C_{\mathrm{O}}$ - initial and final concentration of phenol before and after the adsorption process, respectively $(\mathrm{mg} / \mathrm{l})$;

$m$ - the amount of adsorbent (sea lettuce) used in experiment $(\mathrm{g})$.

\section{RESULTS AND DISCUSSION}

\section{Characterization of sea lettuce}

\section{Surface area}

The surface area of sea lettuce alga biomass was measured using two methods; the first one was BET (Brunauer-Emmett-Teller) method by isotherm adsorption-desorption of nitrogen gas at $-196.15^{\circ} \mathrm{C}$ using Surface Area Analyzer (Qsurf M1, Thermo CO., USA). The measured surface area was $4.526 \mathrm{~m}^{2} / \mathrm{g}$. The other method was achieved using methylene blue dye; the value determined was $379.724 \mathrm{~m}^{2} / \mathrm{g}$, i.e. much higher than in the case of the BET number. The reason for this great discrepancy between the two results is attributable to the different adsorption mechanism of the $\mathrm{N}_{2}$ molecules by the sea lettuce alga biomass in the first method and the blue dye molecules in the second one. The sea lettuce alga swells in the wet state and its porous structure is filled with water, while this phenomenon did not occur when nitrogen gas was adsorbed.

\section{Fourier transform infrared (FTIR)}

The Fourier Transform Infrared (FTIR) analysis was carried out at room temperature for powdered sample of sea lettuce using FTIR spectrophotometer, Irprestige-21, Shimadzu, Japan with equipment resolution of $\left(\mathrm{cm}^{-1}\right)$ to identify the chemical functional groups founded in the surface of alga (Ulva lactuca) in wave number region (4000-400 $\left.\mathrm{cm}^{-1}\right)$. Figure 2a represents the FTIR analysis of sea lettuce before phenol absorption, while the FTIR after adsorption is shown in Figure 2b. From the FTIR spectrum in Figure 2a, it is obvious that there are different absorption bands representing seven functional groups. The first functional group was $-\mathrm{OH}$ represents by $3398.12 \mathrm{~cm}^{-1}$ wave number, while the second functional group was $\mathrm{N}-\mathrm{H}$ represented by $3058.85,3037.28,2966.40,2933.41$ and $2873.61 \mathrm{~cm}^{-1}$ wave number. The third functional group was $\mathrm{C}=\mathrm{O}$ represented by 1739.63 , 1607.72 and $1581.86 \mathrm{~cm}^{-1}$ wave number. The fourth functional group was $\mathrm{N}=\mathrm{O}$ represented by $1509.65,1459.63,1384.28$ and $1362.86 \mathrm{~cm}^{-1}$ wave number. The fifth functional group was C-O represented by $1295.81,1243.52,1182.54$, 1106.29 and $1041.07 \mathrm{~cm}^{-1}$ wave number, while the sixth functional group was $\mathrm{C}-\mathrm{X}$ represented 
a)

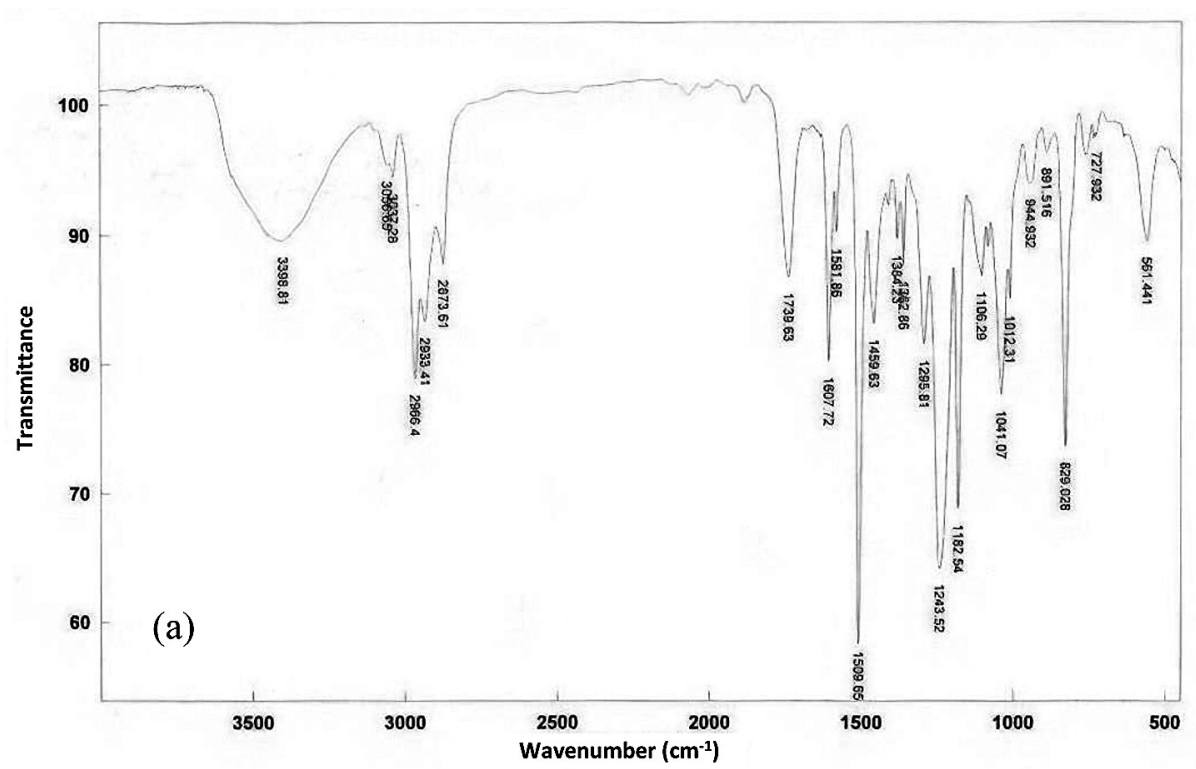

b)

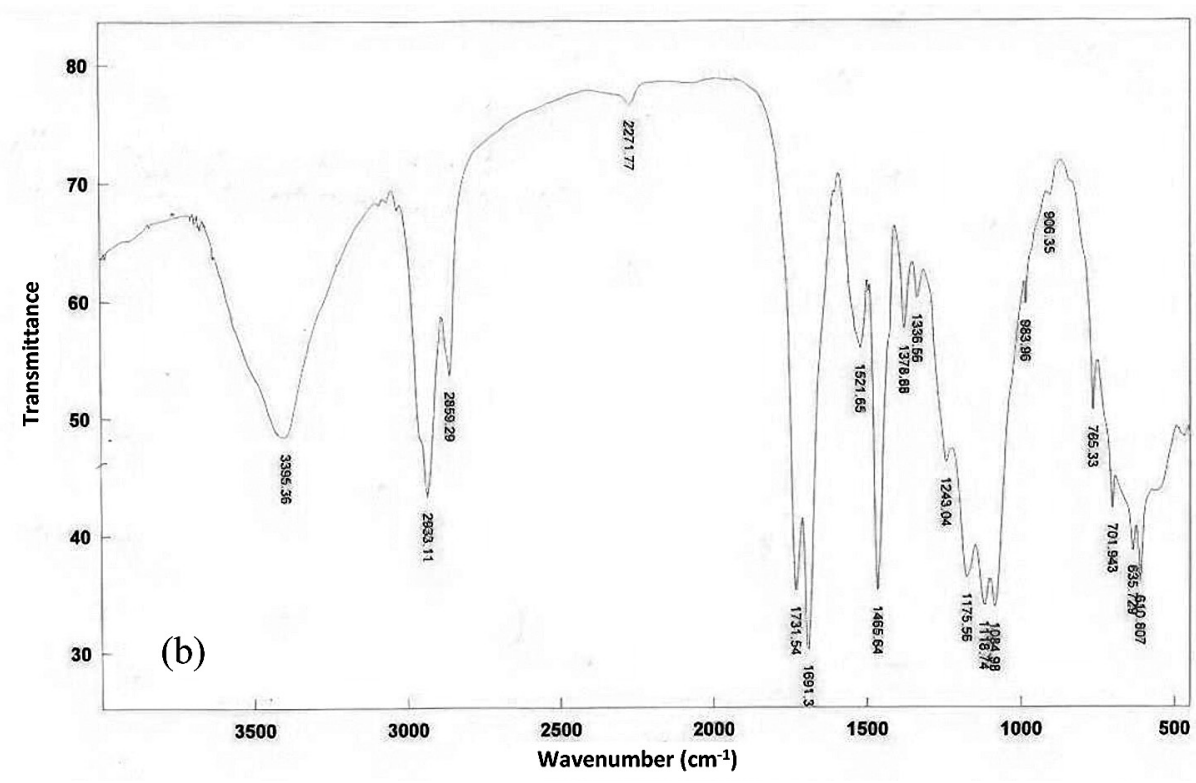

Figure 2. FTIR spectrum of sea lettuce (a) before and (b) after adsorption of phenol

by 1012.31 and $561.441 \mathrm{~cm}^{-1}$ wave number. The final functional group was $\mathrm{C}-\mathrm{H}$ represented by 944.932, 891.516, 892.028 and $727.932 \mathrm{~cm}^{-1}$ wave number.

\section{Scanning electron microscopy (SEM)}

The morphology study of the Ulva lactuca surface was studied by Scanning Electron Microscopy (SEM) equipment (multi-function scanning electron microscope model AIS 2300C Angstrom, USA) before and after adsorption of phenol from aqueous solutions. The samples were sputter coated with gold using (Fine coat JFC-1100E, JEOL Co., Japan) ion sputter in order to reduce the charging effect.
Figure 3a explains that the surface of the sea lettuce biomass cells before contact with phenol solution, was uniform and smooth. In contrast, Figure $3 \mathrm{~b}$ shows the damage happened after the exposure to solution of phenol. The surface of the biomass became surface while the cells were puffed up and deteriorated due to the phenol molecules accumulation inside the cells and attached with the functional groups found on the wall which were identified by the FTIR test. The ions resulting from phenol ionization exchange the strong cross linked metals and complexes cations by free binding sites inside the cell wall and occupied their sites due to ion exchange mechanism. 

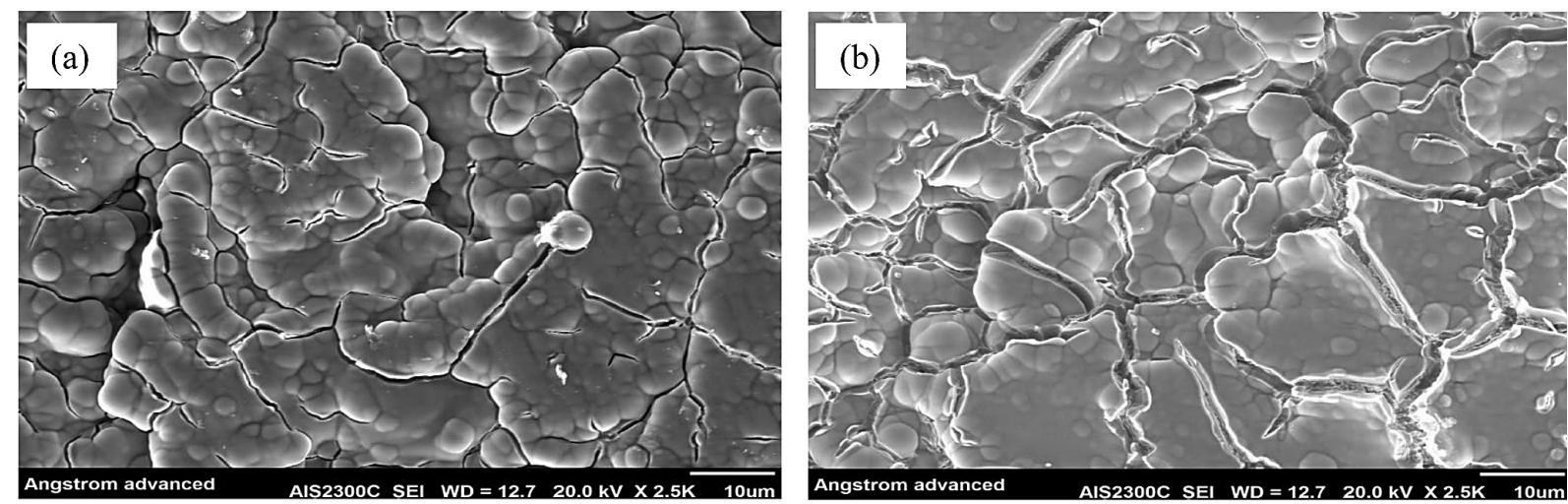

Figure 3. SEM of sea lettuce (a) before and (b) after phenol adsorption

\section{Adsorption process}

\section{Influence of $\mathrm{pH}$}

The study on the significant role played by $\mathrm{pH}$ in the removal process of phenol from wastewater was performed in this investigation via changing the $\mathrm{pH}$ value of wastewater from 2 to 11 including all the three ranges of $\mathrm{pH}$ (i.e. acidic, neutral and basic) and the data obtained was represented graphically in Figure 4a. The figure indicates that using see lettuce powder as a biosorbent material, the percentage removal of phenol decreased when the $\mathrm{pH}$ of wastewater increased at constant other variables at under optimum conditions. The decrease of adsorption efficiency may be attributed to several reasons such as the increasing in hydroxide ions $\left(\mathrm{OH}^{-}\right)$which is related with increasing the $\mathrm{pH}$ value of the solution, so the dissociation of phenol to phenolate increases as well. This will lead to the occurrence of a significant repulsion force between phenolate ions together or with hydroxide ions in the same solution. Thus, the removal efficiency will decrease because the chance of ions attractive and adsorbate on the biomass surface is decreased. On the other hand, at the lower value of solution $\mathrm{pH}$, the phenol tendency towards dissociation is lesser and compels the surface of the biosorbent material to charge with positive charges which leads to more attractive force than adsorption between the molecules on the surface and the phenol molecules. The best acidic $\mathrm{pH}$ value of phenol solution was 2, which gives higher percentage removal of phenol by sea lettuce powder, is selected as a favorite value of $\mathrm{pH}$ for further experiments of other parameters.

\section{Influence of temperature}

In general, temperature is considered as one of the most important parameters in the adsorption process, through which the nature of the process (endothermic or exothermic) can be determined. In this study, the effect of temperature on the process of phenol adsorption by sea lettuce powder in different temperatures was carried out within the range of $20-50^{\circ} \mathrm{C}$. The results obtained from practical experiments were shown in Figure 4b. It was noted from the results that the process of phenol adsorption on the surface of sea lettuce algae was exothermic process as the removal percentage decreases by increasing the temperature, keeping all other variables constant under optimum conditions. The result of this finding may be attributed to the increasing temperature which leads to a decrease in the adsorptive forces between the phenol molecules and the active sites on the surface of the biosorbent material where the kinetic energy of the molecules on the surface would be increased. On the other hand, the interaction between the phenol molecules and the adsorptive surface will decrease, thus reducing the diffusion within the active sites. This may be lead to an increase in the probability of their separation from the adsorptive surface and return it to the solution. Moreover, the temperature increasing leads to an increase in phenol solubility (phenol solubility is 82.8 and $117.7 \mathrm{mg} / \mathrm{L}$ at 20 and $50^{\circ} \mathrm{C}$, respectively) leading to decreased the adsorption efficiency. As a result, the percentage removal of phenol will be reduced by rising temperatures. This result is consistent with the thermodynamic requirements of the adsorption process. 


\section{Influence of agitation speed}

Agitation speed effect was studied by altering its value from 100 to $500 \mathrm{rpm}$, while keeping the other factors are constant under optimum conditions. The effect of agitation speed on adsorption removal efficiency of phenol is illustrated in Figure 4c. As can be seen from Figure 4c, the removal efficiency of phenol from wastewater is increased along with the agitation speed (i.e. proportional relation). This is due to two facts, the first one is the increase of agitation speed, which improves the diffusion of phenol ions from the wastewater towards the adsorbent material (sea lettuce powder) that have empty active sites in the pore and can attached the phenol or phenolate ions via the functional groups on its surfaces. The other fact is that the thickness of boundary layer around the particles of adsorbent media decreases with increased turbulence. Additionally, the same figure indicates that at 400 $\mathrm{rpm}$, the maximum adsorption capacity of sea lettuce alga was reached, but beyond this value there is no further increase in the adsorption efficiency of the adsorbent biomass. This means that the optimum speed for adsorption process using sea lettuce biosorbent is $400 \mathrm{rpm}$.

\section{Influence of contact time}

The effect of contact time on the percentage removal efficiency of phenol from wastewater is shown in Figure $4 \mathrm{~d}$ when other variables are constant at the optimum values. The results demonstrated that when the contact time of adsorption process was increased, the remediation of phenol improved as well until constant, by reaching 120 minutes. This may be attributed to the fact that when the contact time of polluted solution was increasing and the agitation velocity of wastewater in shaker with the adsorbent material (sea lettuce) was remained constant, phenol spent longer time in contact with biosorbent media than when the time of treatment decreased, so the sea lettuce powder took up a greater more amount of phenolate ions from SSAS feed; therefore the percentage removal of phenol from polluted solution increased. Figure $4 \mathrm{~d}$ also showed that the adsorption efficiency increases dramatically and suddenly in the first ten minutes, then the adsorption rate gradually increases until it reaches the equilibrium state at 120 minutes. This result can be attributed to the fact that at the beginning of the adsorption process, the number of active sites on the surface of the biosorbent material (i.e. sea lettuce) is very large and over time the rate decreased progressively due to the attachment with phenol molecules or phenolate ions. The decrease in the number of active sites continues until saturation is achieved, a state of equilibrium in which the attachment molecules to the surface is equal to the number of absorbent particles that leave it.

\section{Influence of adsorbent material dose}

The effect of the adsorbent material dose on the adsorption process efficiency of phenol was tested based on the results of the practical experiments, which were carried out using between 1-5 $\mathrm{g}$ of sea lettuce powder and the rest of the other variables were constant at optimum parameters. The results obtained from the study of this factor indicate that there is a direct relationship between the percentage of phenol removal and the dose of adsorbent media, meaning that when the amount of sea lettuce powder in the adsorption unit was diminished, the efficiency of phenol adsorption was reduced, as shown in Figure 4e; the highest removal percentage of phenol was obtained at the quantity of $5 \mathrm{~g}$. This result can be explained by relying also on the active sites in the adsorbent material. When the amount of biomass was low, the surface area and the number of active sites would be small too. Therefore, the number of phenol molecules that were adsorbed from the pollutant solution on the surface of the adsorption media would be lower compared with the amount of molecules that are adsorbed when the dose of the adsorbent was greater. Thus, the percentage of removal of phenol molecules from contaminated water solutions will improve by increasing the dose of the adsorbent material (sea lettuce powder) in the adsorption unit.

\section{Influence of phenol initial concentration}

The results showed that using sea lettuce powder as an adsorbent media, the percentage removal of phenol from the polluted solution was decreased when the initial concentration was increased, keeping other factors at optimum values as shown in Figure 4f. This can be explained by the fact that the initial concentration of phenol had a restricted effect on the removal capacity; simultaneously, the adsorbent media has a limited number of active sites, which would become saturated at a certain concentration of phenol. This led to an increase in the number of phenol 

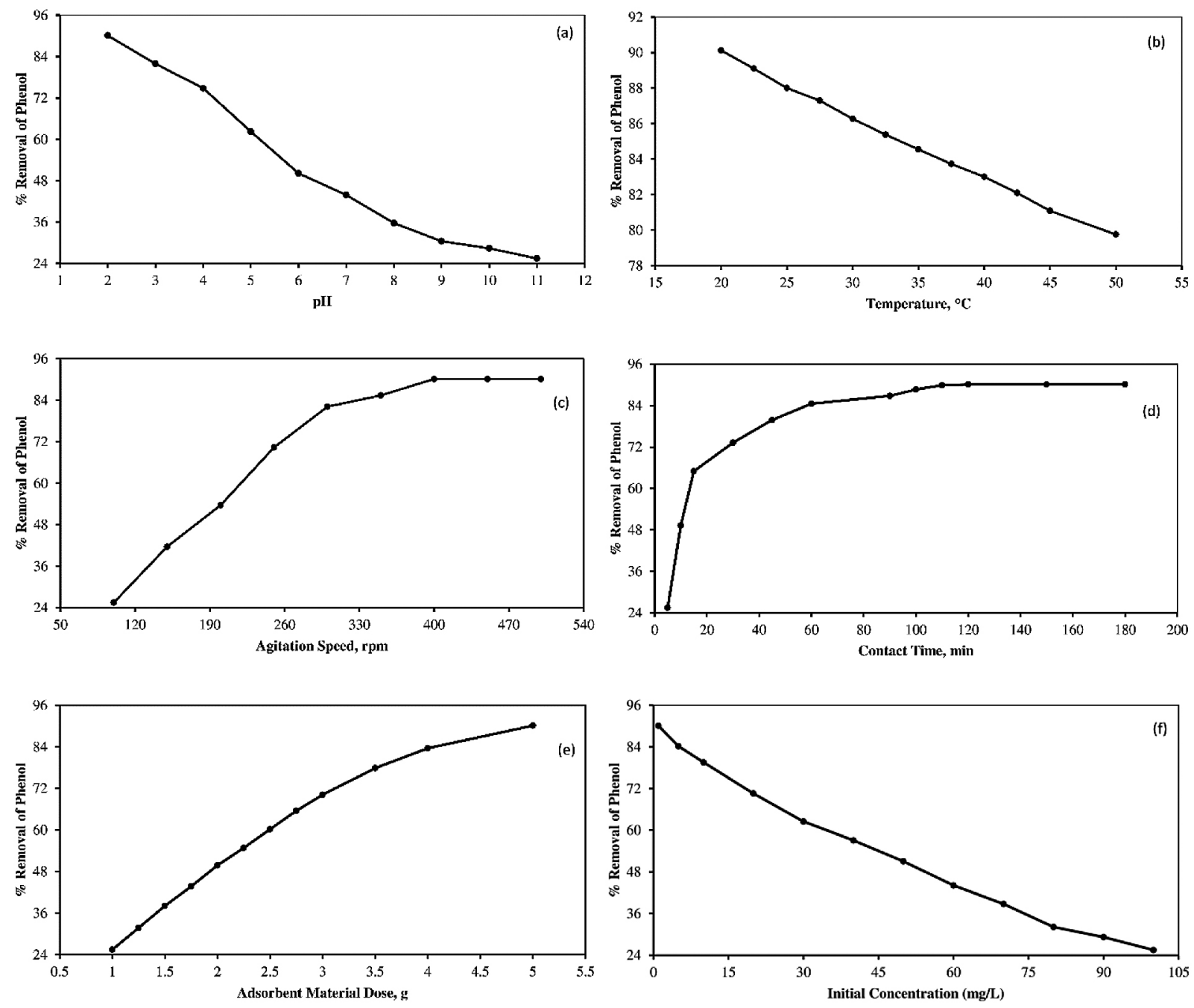

Figure 4. Effect of operation parameters on the removal percent

molecules competing for the available active sites on the surface of the adsorbent media. Since the polluted solution of lower concentration has a smaller amount of phenol molecules than the solution of higher concentration; therefore, the percentage removal was decreased with increasing initial concentration of polluted phenol. The highest percentage removal of phenol was $91.125 \%$ and $25.446 \%$, at initial phenol concentration of 1 and $100 \mathrm{mg} / \mathrm{l}$, respectively. Thus, this adsorbent media (sea lettuce alga) was found to be efficient in removing polluted phenol from aqueous solutions.

\section{Adsorption Isotherm}

\section{Langmuir isotherm model}

The Langmuir isotherm model of adsorption is a semi-empirical relation derived from a proposed kinetic mechanism of molecules. This model suggested that the adsorption surface was homogenous, the adsorbed molecules do not react with each other and the adsorption was carried out in a monolayer and equivalent. The Langmuir isotherm model of adsorption can be described by equation (2):

$$
, q_{e}=\frac{q_{\max } \cdot K_{L} C_{e}}{1+K_{L} C_{e}}
$$

While the mathematical linear expression of Langmuir model is given by equation (3):

$$
\frac{1}{q_{e}}=\frac{1}{q_{\max } K_{\mathrm{L}}} \frac{1}{C_{e}}+\frac{1}{q_{\max }}
$$

where: $q_{e}-$ adsorption capacity at the equilibrium $(\mathrm{mg} / \mathrm{g})$,

$C$ - adsorbed concentration at the equilibrium (mg/l),

$K_{L}$ - Langmuir constant, expressed the binding sites $(1 / \mathrm{mg})$,

$q_{\max }-$ maximum adsorption capacity $(\mathrm{mg} / \mathrm{g})$. 


\section{Freundlich isotherm model}

The Freundlich isotherm model is an empirical model that describes the relation between the solute concentration on the adsorbent surface and the solute concentration in the liquid bulk which in contact with it. This model supposes that there was multilayer for adsorption and the surface of adsorption was heterogeneous, while the active sites were non-equivalent or independent. However, Freundlich isotherm model can be described by the equation (4) below:

$$
q_{e q}=K_{F} C_{e q}^{\frac{1}{n}}
$$

Equation (5) shows the linear form of Freundlich isotherm:

$$
\ln q_{e}=\ln K_{\mathrm{F}}+\frac{1}{n} \ln C_{e}
$$

where: $K_{F}-$ Freundlich constant represent the measured capacity of adsorption $\left[(\mathrm{mg} / \mathrm{g}) \cdot(1 / \mathrm{mg})^{1 / \mathrm{n}}\right]$, $n-$ intensity of adsorption (-).

The parameters of adsorption isotherm were determined from the intercepts and slopes of Langmuir isotherm and Freundlich isotherm and listed in Table 1. The values of calculated correlation coefficients $R^{2}$ were higher for the Langmuir isotherm than the Freundlich isotherm; that means Langmuir isotherm model represented the adsorption process well than Freundlich isotherm model. The maximum capacity of sea lettuce powder for phenol removal was $0.02726 \mathrm{mg} / \mathrm{g}$ at constant temperature that indicated the best adsorbing capacity of sea lettuce for phenol removal.

\section{Adsorption kinetics}

In this investigation, the kinetics of phenol adsorption was studied due to its important role in determining the physical and chemical behavior of the adsorbent media and also predicting the mechanism of adsorption process occurred. Three kinetic models were proposed to investigate the experimental data obtained from the adsorption of phenol on sea lettuce. These kinetic models are first order reversible model, pseudo first order model and pseudo second order model.

\section{Pseudo-first order model}

This model is dependent on the capacity of solid adsorbate. It is assumed that the adsorption between liquid and solid occurred on one layer on the adsorption surface (adsorbate). The mathematical expression of this model is described by Equation (6):

$$
q_{e q}-q=e^{-k_{1} t}
$$

where: $q_{e q}$-is the cyanide ion quantity adsorbate per unit mass of adsorbent at equilibrium $(\mathrm{mg} / \mathrm{g})$,

$q-$ is the cyanide ion quantity adsorbate per unit mass of adsorbent at any time $(\mathrm{mg} / \mathrm{g})$,

$t$ - is the time,

$k_{1}-$ is the first order rate constants $\left(\mathrm{min}^{-1}\right)$.

The linear form of this model can be represented by equation (7):

$$
\ln \left(q_{e q}-q\right)=\ln q_{e q}-k_{1} t
$$

So from the plot of $\ln \left(q_{e q}-q\right)$ vs. $t$ it can be calculating the rate constant $k_{+}$which appears as the slop of the equation, while the intercept is equal to $\ln q_{e q}$.

\section{Pseudo-second order model}

Ordinarily, it is the best model for expressing the kinetic model of adsorption process. It is assumed that the adsorption between adsorbent (solid phase) and adsorbent (liquid phase) performed on two layer on the adsorption surface (adsorbate). This model is described by Equation (8):

$$
q=\frac{q_{e q}{ }^{2} k_{2} t}{1+q_{e q}{ }^{2} k_{2} t}
$$

where: $q_{e q}$ - is the cyanide ion quantity adsorbate per unit mass of adsorbent at equilibrium (mg/g),

$q$-is the cyanide ion quantity adsorbate per unit mass of adsorbent at any time ( $\mathrm{mg} / \mathrm{g})$,

Table 1. Langmuir and Freundlich isotherm parameters for the phenol adsorption of on sea lettuce at Optimum Conditions $\left(\mathrm{C}_{\mathrm{o}}=1 \mathrm{mg} \cdot \mathrm{l}^{-1}, \mathrm{pH}=2, \mathrm{~A}_{\mathrm{s}}=400 \mathrm{rpm}, \mathrm{t}=120 \mathrm{~min}, \mathrm{~T}=20^{\circ} \mathrm{C}\right.$ and $\left.\mathrm{D}=5 \mathrm{~g}\right)$

\begin{tabular}{|c|c|c|c|c|c|c|}
\hline \multicolumn{3}{|c|}{ Langmuir Isotherm Model } & \multicolumn{3}{c|}{ Freundlich Isotherm Model } \\
\hline$q_{\max }$ & $K_{L}$ & $R_{L}$ & $R^{2}$ & $K_{F}$ & $n$ \\
\hline 0.02726 & 19.8577 & 0.822 & 0.9988 & 0.0276 & 6.2383 & 0.9372 \\
\hline
\end{tabular}


$t$ - is the time ( $\mathrm{min})$,

$k_{2}-$ is the first second order rate constants $\left(\mathrm{g} \cdot \mathrm{mg}^{-1} \cdot \mathrm{min}^{-1}\right)$.

The linear form of this model can be represented by equation (9):

$$
\frac{t}{q}=\frac{1}{q_{e q}{ }^{2} k_{2}}+\frac{1}{q_{e q}} t
$$

From linearized form, when plotting $(t / q)$ against $\left(1 / q_{e q}\right)$ the slope of equation 8 equals while the intercept is $\left(1 / q_{e q}{ }^{2} k_{2}\right)$. The adsorption kinetic constants and correlation coefficients of three models used in this study were calculated and given in Table 2. Good correlation coefficients $R^{2}$ were observed for the phenol removal process and can be approximated with the pseudo second order kinetics model. Constants for all kinetics models tested were calculated and summarized in Table 2. Thus, the pseudo second order kinetics was pathway to reach the equilibrium.

\section{Adsorption thermodynamic}

Thermodynamic state functions which are change in standard Gibbs free energy $\Delta G^{\circ}$, change in standard enthalpy $\Delta H^{\circ}$ and change in standard entropy $\Delta S^{\circ}$ were calculated using the following thermodynamic equation (Abdelwahab \& Amin, 2013):

$$
\Delta G^{\circ}=\Delta H^{\circ}-T \Delta S^{\circ}
$$

The change in standard free energy $\Delta G^{\circ}$ can be calculated according to the following formula shown in equation (11):

$$
\Delta G^{\circ}=-R T \ln k_{d}
$$

where: $T-$ is absolute temperature, $\mathrm{K}$;

$k_{d}-$ is distribution constant represent the ratio of the phenol concentration at equilibrium on an adsorbent in the solution; $R-$ is universal gas constant.

By substituting the equation in it, equation (12) is obtained:

$$
\ln k_{d}=-\frac{\Delta H^{\circ}}{R} \frac{1}{T}-\frac{\Delta S^{\circ}}{R}
$$

Plot $\ln k_{d}$ vs $1 / T$ gives $-\Delta H^{\circ} / R$ as a slop and $\Delta H^{\circ} / R$ as an intercept. Thus, the value of thermodynamic state functions can be determined. The thermodynamic parameters of phenol adsorption using sea lettuce are listed in the Table 3 .

It is obvious from the table above that all $\Delta G^{\circ}$ are negative; this means that the adsorption process of phenol was spontaneous and feasible. In turn, it is clear that the values of decreased with increasing adsorption temperature. This may mean that the adsorption process achieved on sea lettuce algae is more spontaneous at lower temperature than at the higher one. Due to the values of $\Delta G^{\circ}$ which ranged between (-10 and -9), the adsorption obeyed the physical type.

Table 2. Pseudo first order and pseudo second order results for the adsorption of phenol on sea lettuce under opti-

\begin{tabular}{|c|c|c|c|}
\hline Temperature, $\left({ }^{\circ} \mathrm{C}\right)$ & $\Delta H^{\circ},(\mathrm{KJ} / \mathrm{mol})$ & $\Delta S^{\circ},(\mathrm{J} / \mathrm{mol} \cdot \mathrm{K})$ & $\Delta G^{\circ},(\mathrm{KJ} / \mathrm{mol})$ \\
\hline 20.0 & \multirow{12}{*}{-21.8255} & \multirow{12}{*}{-37.1307} & -10.9676 \\
\hline 22.5 & & & -10.8748 \\
\hline 25.0 & & & -10.7820 \\
\hline 27.5 & & & -10.6892 \\
\hline 30.0 & & & -10.5963 \\
\hline 32.5 & & & -10.5035 \\
\hline 35.0 & & & -10.4107 \\
\hline 37.5 & & & -10.3179 \\
\hline 40.0 & & & -10.2250 \\
\hline 42.5 & & & -10.1322 \\
\hline 45.0 & & & -10.0394 \\
\hline 50.0 & & & -9.85372 \\
\hline
\end{tabular}
mum conditions $\left(\mathrm{C}_{\mathrm{o}}=1 \mathrm{mg} . \mathrm{l}^{-1}, \mathrm{pH}=2, \mathrm{~A}_{\mathrm{s}}=400 \mathrm{rpm}, \mathrm{t}=120 \mathrm{~min}, \mathrm{~T}=20^{\circ} \mathrm{C}\right.$ and $\left.\mathrm{D}=5 \mathrm{~g}\right)$

\begin{tabular}{|c|c|c|c|c|c|c|}
\hline \multicolumn{3}{|c|}{ Pseudo first order } & \multicolumn{3}{c|}{ Pseudo second order } & Experimental \\
\hline$q_{e q}$ & $k_{1}$ & $R^{2}$ & $q_{e q}$ & $k_{2}$ & $R^{2}$ & $q_{e q}$ \\
\hline 0.5811 & $7.441 \times 10^{-3}$ & 0.9022 & 0.0782 & $1.527 \times 10^{-4}$ & 0.9200 & 0.02726 \\
\hline
\end{tabular}

Table 3. The thermodynamic parameters of phenol adsorption using sea lettuce 
Furthermore, the adsorption process on sea lettuce was exothermic because the value of $\Delta H^{\circ}$ was $-21.825 \mathrm{KJ} / \mathrm{mole}$. This indicated that there is a soft bonding between phenol and adsorption sites in the surface of sea lettuce algae, since the phenol molecules adsorbed and breakthrough the inner layers of algae. Moreover, the entropy value of $\Delta S^{\circ}$ was $-37.1307 \mathrm{~J} /$ mole $\cdot \mathrm{K}$, i.e. the freedom degree of adsorption by sea lettuce decreased and the process tended to regulatory piecemeal.

\section{CONCLUSIONS}

Considering the properties sea lettuce algae, it is possible to treat contaminated water with phenol using this biosorbent and the adsorption method. The operating conditions affected the adsorption efficiency. The highest percentage removal of phenol was $90.125 \%$, achieved at optimum parameters which were $\mathrm{pH}=1$, alga dose $=5 \mathrm{~g}$, initial concentration $=1 \mathrm{ppm}$, temperature $=20^{\circ} \mathrm{C}$, treatment time $=120 \mathrm{~min}$ and Agitation speed $=400 \mathrm{rpm}$. The results showed that the Langmuir model was the closer to representing the experimental results obtained than the Freundlich isotherms. The values of $\Delta H^{\circ}$ and $\Delta S^{\circ}$ calculated were $-21.8255 \mathrm{~kJ} / \mathrm{mol}$ and $-37.1307 \mathrm{~J} /$ $\mathrm{mol} \cdot \mathrm{K}$ which indicates that the process of phenol adsorption on the surface of sea lettuce is exothermic and tends to regulatory piecemeal. Moreover, the calculated values of $\Delta G^{\circ}$ ranged between -10 to $-9 \mathrm{KJ} / \mathrm{mol}$ indicating that the adsorption on sea lettuce surface was of a physical type and decreased in spontaneity at higher temperatures. It is obvious from the results obtained that the sea lettuce alga is a biomaterial with significant potential for phenol removal from wastewater. In this way, the toxic compounds contaminating water solutions can be disposed of by means of a substance that is widely available in sea and ocean waters, cost-effective, safe, economical and environmentally friendly method, true the zero residue level (ZRL) concept.

\section{Acknowledgements}

The authors would like to thank the Iraqi universities: Mustansiriyah University (www. uomustansiriyah.edu.iq) Baghdad - Iraq, Tikrit University (http://tu.edu.iq) Tikrit - Iraq, and Diyala University (www.uodiyala.edu.iq) Baqubah - Iraq for their support in the present work.

\section{REFERENCES}

1. Abdelwahab, O., Amin, N. 2013. Adsorption of phenol from aqueous solutions by Luffa cylindrica fibers: Kinetics, isotherm and thermodynamic studies. The Egyptian Journal of Aquatic Research, 39(4), 215-223.

2. Alalwan, H.A., Abbas, M.N., Abudi, Z.N., Alminshid, A.H. 2018. Adsorption of thallium ion (Tl+ 3 ) from aqueous solutions by rice husk in a fixedbed column: Experiment and prediction of breakthrough curves. Environmental Technology \& Innovation, 12, 1-13.

3. Areco, M.M., dos Santos Afonso, M. 2010. Copper, zinc, cadmium and lead biosorption by Gymnogongrus torulosus. Thermodynamics and kinetics studies. Colloids and Surfaces B: Biointerfaces, 81(2), 620-628.

4. Areco, M.M., Hanela, S., Duran, J., dos Santos Afonso, M. 2012. Biosorption of $\mathrm{Cu}$ (II), Zn (II), $\mathrm{Cd}$ (II) and $\mathrm{Pb}$ (II) by dead biomasses of green alga Ulva lactuca and the development of a sustainable matrix for adsorption implementation. Journal of hazardous materials, 213, 123-132.

5. Asgari, G., Feradmal, J., Poormohammadi, A., Sadrnourmohamadi, M., Akbari, S. 2016. Taguchi optimization for the removal of high concentrations of phenol from saline wastewater using electro-Fenton process. Desalination and Water Treatment, 57(56), 27331-27338.

6. Banat, F., Al-Bashir, B., Al-Asheh, S., Hayajneh, O. 2000. Adsorption of phenol by bentonite. Environmental pollution, 107(3), 391-398.

7. Basha, S., Murthy, Z., Jha, B. 2008. Removal of Cu (II) and Ni (II) from industrial effluents by brown seaweed, Cystoseira indica. Industrial \& Engineering Chemistry Research, 48(2), 961-975.

8. Chen, Y., Dong, R., Peng, G., Yi, Z., Huo, S., Liu, Y., Pang, C. 2011. Cultivation of Chlorella sp. in anaerobic effluent for biomass production. Environmental Engineering \& Management Journal (EEMJ), 10(7).

9. Cheng, W., Quan, X., Li, R., Wu, J., Zhao, Q. 2018. Ozonation of phenol-containing wastewater using O3/ $\mathrm{CaOH}_{2}$ system in a micro bubble gas-liquid reactor. Ozone: Science \& Engineering, 40(3), 173-182.

10. D'Alessandro, O., Thomas, H., Sambeth, J.E. 2014. Removal of phenol from aqueous solutions by adsorption onto $\mathrm{Mn}-\mathrm{Ce}-\mathrm{K}$ solids. Reaction Kinetics, Mechanisms and Catalysis, 113(1), 257-267.

11. Davis, T., Volesky, B., Vieira, R. 2000. Sargassum seaweed as biosorbent for heavy metals. Water research, 34(17), 4270-4278.

12. Gavrilescu, M. 2004. Removal of heavy metals from the environment by biosorption. Engineering in Life Sciences, 4(3), 219-232. 
13. Lazo-Cannata, J.C., Nieto-Márquez, A., Jacoby, A., Paredes-Doig, A.L., Romero, A., Sun-Kou, M.R., Valverde, J.L. 2011. Adsorption of phenol and nitrophenols by carbon nanospheres: Effect of $\mathrm{pH}$ and ionic strength. Separation and purification Technology, 80(2), 217-224.

14. Lin, S.-H., Juang, R.-S. 2009. Adsorption of phenol and its derivatives from water using synthetic resins and low-cost natural adsorbents: A review. Journal of Environmental Management, 90(3), 1336-1349.

15. Lodeiro, P., Barriada, J., Herrero, R., De Vicente, M.S. 2006. The marine macroalga Cystoseira baccata as biosorbent for cadmium (II) and lead (II) removal: kinetic and equilibrium studies. Environmental pollution, 142(2), 264-273.

16. Nakhli, S.A.A., Ahmadizadeh, K., Fereshtehnejad, M., Rostami, M.H., Safari, M., Borghei, S.M. 2014. Biological removal of phenol from saline wastewater using a moving bed biofilm reactor containing acclimated mixed consortia. SpringerPlus, 3(1), 112.

17. Olya, M.E., Pirkarami, A. 2013. Electrocoagulation for the removal of phenol and aldehyde contaminants from resin effluent. Water Science and Technology, 68(9), 1940-1949.

18. Park, D., Yun, Y.-S., Ahn, C.K., Park, J.M. 2007. Kinetics of the reduction of hexavalent chromium with the brown seaweed Ecklonia biomass. Chemosphere, 66(5), 939-946.
19. Sar1, A., Tuzen, M. 2008. Biosorption of Pb (II) and $\mathrm{Cd}$ (II) from aqueous solution using green alga (Ulva lactuca) biomass. Journal of Hazardous Materials, 152(1), 302-308.

20. Senturk, H.B., Ozdes, D., Gundogdu, A., Duran, C., Soylak, M. 2009. Removal of phenol from aqueous solutions by adsorption onto organomodified Tirebolu bentonite: Equilibrium, kinetic and thermodynamic study. Journal of hazardous materials, 172(1), 353-362.

21. Turner, A., Lewis, M.S., Shams, L., Brown, M.T. 2007. Uptake of platinum group elements by the marine macroalga, Ulva lactuca. Marine Chemistry, 105(3-4), 271-280.

22. Vaiano, V., Matarangolo, M., Murcia, J.J., Rojas, H., Navío, J.A., Hidalgo, M.C. 2018. Enhanced photocatalytic removal of phenol from aqueous solutions using $\mathrm{ZnO}$ modified with Ag. Applied Catalysis B: Environmental, 225, 197-206.

23. Wang, X., Ou, H., Huang, J. 2019. One-pot synthesis of hyper-cross-linked polymers chemically modified with pyrrole, furan, and thiophene for phenol adsorption from aqueous solution. Journal of Colloid and Interface Science, 538, 499-506.

24. Yang, X., Zou, A., Qiu, J., Wang, S., Guo, H. 2014. Phenol removal from aqueous system by Bis (2-ethylhexyl) sulfoxide extraction. Separation Science and Technology, 49(16), 2495-2501. 